\title{
Erratum
}

Int Neurourol J 2011;15:181

http://dx.doi.org/10.5213/inj.2011.15.3.181

pISSN 2093-4777 · eISSN 2093-6931

\section{Author's Name Correction}

Int Neurourol J 2010;14:164-9. Published online 2010 October 31.

http://dx.doi.org/10.5213/inj.2010.14.3.164

\section{Tape Shortening for Recurrent Stress Urinary Incontinence After Transobturator Tape Sling: 3-Year Follow-up Results}

Seol Kim, Jun Ho Son, Hyo Sin Kim, Jun Sung Ko, Joon Chul Kim

One of the author's names was misprinted. The author list should be corrected as follows.

\section{Corrected author list}

Seol Kim, Jun Ho Sohn, Hyo Sin Kim, Jun Sung Ko, Joon Chul Kim 